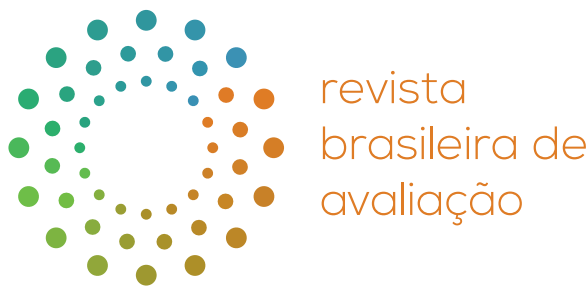

\title{
Avaliação no contemporâneo: Dilemas e desafios
}

\section{Contemporary evaluation: Dilemmas and challenges}

\author{
Oswaldo Yoshimi Tanaka ${ }^{1 *}$ [Amarelo] (D) \\ ${ }^{1}$ Universidade de São Paulo (USP), Faculdade de Saúde Pública, São Paulo, SP, Brasil
}

COMO CITAR: Tanaka, Oswaldo Yoshimi. (2021). Avaliação no contemporâneo: Dilemas e desafios. Revista Brasileira de Avaliação, 10(1), e100721. https://doi.org/10.4322/rbaval202110007

\section{Resumo}

O presente artigo de opinião apresenta reflexões do autor sobre processos avaliativos contemporâneos. Nele são abordados possíveis alcances e limites de distintas abordagens metodológicas utilizadas em processos de tomada de decisão em políticas públicas, explorando as relações entre avaliação e processos decisórios. $\mathrm{O}$ artigo procura trazer reflexões sobre dilemas da utilização de planos de análise baseados em evidências e da aplicação de questionários validados, os quais necessitam ser contextualizados e adequados ao contexto e objetos avaliados. Deste modo, identifica e discute alguns desafios para a avaliação contemporânea como respostas às necessidade das decisões em políticas públicas.

Palavras-chave: Avaliação e tomada de decisão. Utilidade da avaliação. Políticas públicas.

\section{Abstract}

This opinion article presents the author's reflections on contemporary evaluation processes. It addresses possible scope and limits of different methodological approaches used in decision-making processes in public policies, exploring the relationship between evaluation and decision-making processes. The article seeks to bring reflections on dilemmas regarding the use of evidence-based analysis plans and the application of validated questionnaires, which need to be contextualized and adapted to context and evaluative objects. It also identifies and discusses some challenges for contemporary evaluation as responses to the need for public policy decisions.

Keywords: Evaluation and decision making. Evaluation utility. Public policies.

Recebido: Outubro 23, 2020 Aceito: Dezembro 08, 2020

*Autor correspondente: Oswaldo Yoshimi Tanaka E-mail: oytanaka@usp.br

\section{(cc) BY}

Este é um artigo publicado em acesso aberto (Open Access) sob a licença Creative Commons Attribution, que permite uso, distribuição e reprodução em qualquer meio, sem restrições desde que o trabalho original seja corretamente citado. 
A prática avaliativa sempre se deu em situações e terrenos complexos. Há grandes apelos por objetividade, pautas políticas sempre em disputa, escolhas que precisam ser feitas pelos gestores e necessidades de se produzir avaliações apoiadas em parâmetros científicos com algum rigor. Mais recentemente, como se lê nos jornais de grande circulação, nas revistas científicas e nos espaços de formação em avaliação, há enorme apelo por evidências. Ao mesmo tempo, há atores, tempos políticos, recursos escassos e demandas por maior participação, o que torna desafiadora a arena avaliativa. Este artigo foi escrito para problematizar tais elementos e para colocar em debate algumas percepções e opiniões.

Comecemos pelo tema das evidências. O conceito de evidência no jargão policial é definido como aquilo que permite tornar alguém réu por alguma circunstância que é, por si só, evidente. Nestes casos, não é preciso ter muitas provas porque a evidência é a prova cabal. Quando tomamos o conceito de evidência no conhecimento científico, e depois na gestão, falamos de um suposto conhecimento tão bem estruturado e tão bem descrito que, per si, é capaz de dizer se uma coisa é ou não; é capaz de comprovar um resultado. No campo da diagnóstica em saúde, a evidência é aquilo que permite dizer que o profissional irá determinar uma causa e que está perto de um diagnóstico definitivo.

É nesse sentido que as evidências querem sustentar inferências sobre causalidade. Os discursos em torno das evidências vêm de um conhecimento científico de forte vertente clínica e, por isso, associado aos modelos experimentais. Por isso as evidências valorizam bastante as tecnologias de diagnóstico e de tratamento. Ao trabalhar com tecnologias duras como o diagnóstico e a terapêutica ligados a processos clínicos, as evidências têm bastante importância. Mas é aqui que temos um tipo de virada. Na saúde pública/coletiva, apesar do conceito de evidência também ter elevada importância, o universo no qual os estudos são realizados não permitem o mesmo grau de inferência e presunção de causalidade que se tem na área clínica, e esta é uma ressalva de cautela para utilização de evidências.

Cabe reconhecer que os gestores, tanto na esfera privada quanto pública, têm procurado evidências na expectativa de errar menos nas condições incertas em que atuam, o que em muitos casos já é um grande avanço. Como podemos perceber, as condições sociais nas quais produzimos políticas de saúde, meio ambiente, educação, assistência, entre outras, têm hoje muito mais incertezas do que certezas. Levanto a hipótese de que as evidências na área de saúde pública/coletiva não são tão potentes quanto são na área clínica. Por isso uma das estratégias para se processar as incertezas é a utilização de abordagens participativas desde o início das avaliações, partindo da formulação de perguntas avaliativas com todos os interessados, de maneira que tanto a escolha dos indicadores quanto a definição dos parâmetros sejam reconhecidos por eles e relevantes nos processos decisórios.

Habitualmente os gestores procuram evidências visando gerar um cenário mais propenso para demonstrar resultados. Em outros tempos, como na prática de saúde nos anos 1970, os gestores tinham muito menos dúvidas e inseguranças; sabia-se que $80 \%$ de cobertura vacinal controlava a doença. Sabia-se que administrar um antibiótico de espectro gram-positivo trataria uma determinada infecção. Na medida em que a oferta de conhecimentos mudou, que mais atores entraram em cena e que alguns novos fenômenos sociais emergiram, as relações ficaram mais complexas e a multicausalidade ganhou significado. As decisões ganharam um grau de incerteza muito maior, seja na ciência ou na política.

Políticos e gestores dependem de algum outro conhecimento que não apenas a dinâmica política e institucional na qual estão inseridos. Eles buscam evidências que permitam decidir melhor. Seja se apoiando em experiências controladas ou não, o desejo dos gestores, ou talvez sua fantasia, é a capacidade de controlar variáveis e tornar mais assertivas as relações ou associações. Ao mesmo tempo, quando observamos sistemas complexos, sabemos que neles são inevitáveis as inseguranças nos processo de decisão ou de associação. Mesmo que você tenha evidências, há insegurança de que elas serão capazes de indicar a melhor estratégia a ser desenvolvida.

Vejamos outro exemplo bastante delicado, mas necessário ao debate. Na questão do Covid 19, já no início da pandemia, havia claras evidências científicas mostrando que o distanciamento social era a melhor alternativa. Estudos de transmissibilidade com evidências trazidas da 
epidemiologia de doenças infecciosas mostravam que se afastássemos o foco das pessoas elas se contaminariam menos, com menos casos e óbitos. Parte dos políticos e gestores, contudo, começou a dizer outra coisa: "bom, mas isso que vocês estão chamando de evidência está desestruturando nosso sistema econômico-social" e "isso que vocês dizem que é verdade, não é verdade absoluta". Foi quando nos deparamos com outras variáveis que informaram as decisões, como a hidroxicloroquina, que foi tomada como adequada sem que houvesse evidência científica para tal. Tendo em vista que questões econômicas influenciam a tomada de decisão em políticas públicas, este caso ajudou a observar que cada ator quer reunir evidências para respaldar sua decisão e que cada parte interessada poderá apresentar dados, mais ou menos consistentes, para justificar suas decisões.

Mas se os dilemas são muitos, é preciso reconhecer também o crescente interesse pelas avaliações, o que inclui práticas, formação e publicações. E parece também viver nesta ampliação do campo avaliativo grande contradição: muitos de nós temos receio de errar em avaliação; errar no sentido de não fazer uma avaliação adequada e reconhecida pelos pares. E parece que isso tem nos levado a ser muito mais capturados pelo método, pelos frameworks ou por definições validadas de como realizar uma avaliação. Esta situação tem nos tornado pouco ousados em flexibilizar frameworks e misturar abordagens com vistas a assegurar avaliação no tempo oportuno da tomada de decisão.

É o caso da aplicação de questionários, por exemplo. É habitual entre pesquisadores avaliadores a preocupação pela utilização de um instrumento validado por outro pesquisador. Entretanto, cabe destacar que essa condição não necessariamente atende às características do contexto e tampouco do objeto da avaliação. É quando cabe aos avaliadores a análise crítica de um questionário, validado ou não, em busca de melhor compreender se ele permite captar as variáveis necessárias ao plano de análise, se ele vai possibilitar um bom exercício de valoração. Por isso parece oportuno pensar se o modo como temos compreendido o método científico tem nos pressionado a apenas reproduzir modelos e refletir pouco sobre sua adequação.

Esta afirmação não quer dizer que o uso de questionários e métodos validados seja ruim. Quer sim colocar em perspectiva que é sempre útil considerar o quanto nossas escolhas metodológicas diminuem ou ampliam a participação de atores nos processos de decisão, o quanto assegura ou reduz o papel social de alguém que precisa produzir informação no tempo da decisão política. Como sabemos, todas as vezes que deixamos de identificar quem está tomando as decisões, deixamos de analisar os poderes que estão em jogo. Se quisermos que uma avaliação seja efetivamente útil, é preciso mapear qual poder está em jogo. Se há potenciais ganhos no uso de frameworks, é preciso ponderar se nossas escolhas não estão nos fazendo perder uma parte essencial: como é que nós, atores sociais neste processo social tão complexo, estamos realmente contribuindo para produzir estudos de custo-efetividade?

Neste sentido, talvez haja um convite para que os avaliadores evitem prender-se demais às técnicas enquanto distanciam-se da política e da leitura das forças em jogo. Reparemos, por exemplo, que se na pesquisa avaliativa feita na academia disponibilizamos métodos e resultados que podem ser úteis em tomadas de decisão, o que pode resultar na efetiva alteração de uma intervenção, na avaliação de políticas públicas é possível que não estejamos suficientemente atentos a análises mais aprofundadas da questão política, quando avaliamos.

Nesse sentido, os avaliadores acreditam que se têm uma boa hipótese, uma boa metodologia, técnicas adequadas de coleta e um plano de análise, a avaliação será capaz de ajudar no processo de decisão; acredito que esta pode ser uma crença de parte de nós, principalmente porque vários avaliadores continuam trabalhando na universidade. Contudo, o que o Século XXI tem nos mostrado, especialmente do que vivenciamos com a Covid 19, é que tais etapas do método científico não têm sido valorizadas na tomada de decisão. Será desafiador mas necessário aproveitar ao máximo a oportunidade de praticar análises de poder nas decisões em políticas sociais, principalmente em saúde.

A título de exemplo, tomemos o caso do Sistema Único de Saúde (SUS). São 30 anos nos quais batalhamos e perseguimos fortemente um sistema universal de justiça social, que fosse suficiente para produzir universalidade, integralidade e equidade. A gestão tripartite (união, 
estados e municípios) facilitou a dimensão de universalidade mas se encontra fragilizada na busca da integralidade e equidade, em parte decorrente do financiamento insuficiente. Existe uma forte disputa entre os três níveis. Há imensa sobrecarga do nível municipal em busca da universalidade. O nível estadual está focado na integralidade e buscando expandir a média complexidade, com o nível federal com frágil coordenação e dificuldades de financiamento.

Nesse novo cenário, em que os três entes federados estão muito mais dependentes do setor privado para cumprirem os princípios da Constituição de 1988, há grandes desafios para a avaliação do SUS. Um desses é a articulação da rede de atenção básica com os serviços de média complexidade, por serem esses gerenciados por organizações sociais que funcionam de forma independente do setor público. Essa frágil integração também ocorre com o nível terciário de complexidade, essencialmente concentrado em alguns poucos municípios de grande porte. A carência de diretrizes estratégicas neste caso dificulta as avaliações que buscam compreender a articulação entre os distintos níveis de complexidade para a construção das regiões de saúde.

Se quisermos tomar outro exemplo de política pública, basta olhar o campo da educação, em que vários projetos são frequentemente implementados de forma desarticulada. Infelizmente o modelo econômico vigente tem mantido a desigualdade sócio econômica e a política educacional não tem sido suficiente para alcançar as mudança estruturais necessárias. A saúde e a educação per se não são capazes, isoladamente, de contrapor a desigualdade. Consequentemente há limites para que as avaliações de políticas públicas apoiem a tomada de decisão na busca de equidade.

Isto posto, um grande desafio a ser enfrentado agora parece ser o modo como parte da academia compreende e produz avaliações. De um lado, a produção de estudos ancorados em um rigoroso método científico, cada vez mais cobrado pelas revistas científicas. De outro, a necessidade de produzir avaliações para os tomadores de decisão, sejam do governo ou da sociedade civil, que necessitam de avaliações em exíguos tempos políticos e que podem não ser atendidos pelos desenhos metodológicos propostos pelos pesquisadores.

Talvez por isso o campo avaliativo esteja diante da oportunidade de abrir outras perspectivas, de buscar outras forma de investigar que, baseadas no método científico, possam se sentir autorizadas a inovar e testar caminhos distintos para investigar realidades e identificar associações que possam auxiliar na busca de alternativas de intervenção em políticas públicas. Aí está a potencial utilidade das avaliações.

\section{Fonte de financiamento}

Não há.

\section{Conflito de interesse}

Não há.

\section{Agradecimentos}

O autor gostaria de agradecer a Rogério Silva pelo convite e diálogo que incentivou a produção deste artigo de opinião. 